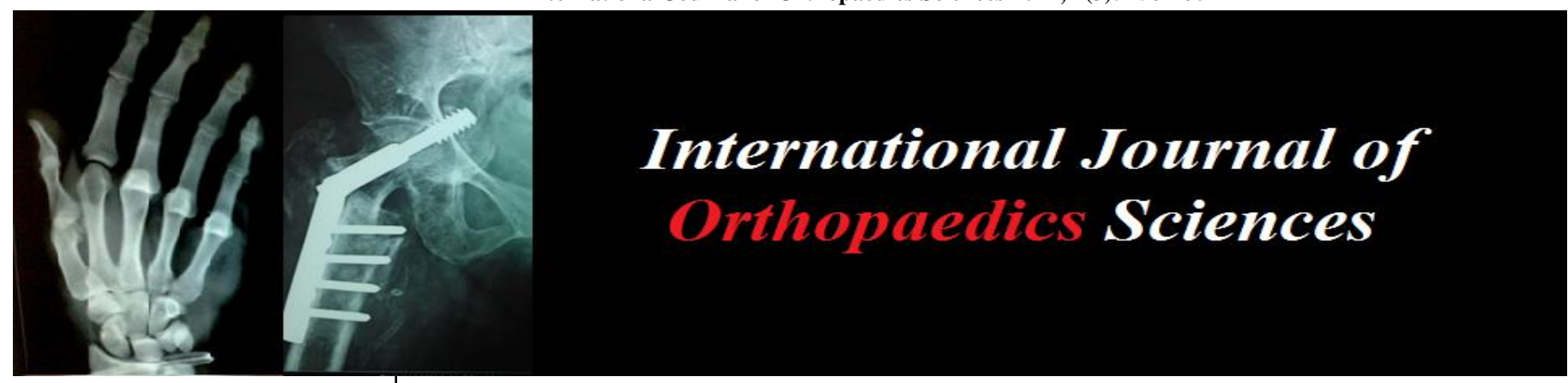

E-ISSN: 2395-1958

P-ISSN: 2706-6630

IJOS 2021; 7(3): 758-760

(C) 2021 IJOS

www.orthopaper.com

Received: 22-05-2021

Accepted: 24-06-2021

Dr. Lalit Phatak

MBBS, MS Orthopaedic

SR Orthopaedics, SHKM, GMC,

Mewat, Haryana, India

Sami Jan

MBBS, Junior Resident, GMC,

Srinagar, Srinagar, Jammu and

Kashmir, India

Gowher Wali

MBBS, Jiangxi University,

Nanchang, China

Shamim Ahmad Bhat

MBBS, MS \& DNB

Orthopaedics, Assistant

Professor, SHKM GMC, Mewat,

Haryana, India

Manjeet Singh Dhanda

MBBS, MS Orthopaedics,

Professor Orthopaedics SHKM,

GMC, Mewat, Haryana, India

Siddhart Goel

MBBS, MS Orthopaedics,

Professor Orthopaedics SHKM,

GMC, Mewat, Haryana, India

Corresponding Author:

Shamim Ahmad Bhat

MBBS, MS \& DNB

Orthopaedics, Assistant

Professor, SHKM GMC, Mewat,

Haryana, India

\section{Chronic trigger finger outpatient basis hypodermic percutaneous release and functional outcome}

\author{
Dr. Lalit Phatak, Sami Jan, Gowher Wali, Shamim Ahmad Bhat, Manjeet \\ Singh Dhanda and Siddhart Goel
}

DOI: https://doi.org/10.22271/ortho.2021.v7.i3k.2830

\section{Abstract}

Trigger finger is a stenosing tenosynovitis producing triggering/ clicking on finger movements along with pain and swelling. This condition although most often involves the thumb, however, any finger of the hand can be involved. Fibrocartilaginous metaplasia of the tendon near the A1 pulley causes nodule formation, resulting in triggering of the finger on finger movements. Treatment of this condition starts with NSAIDS, activity modification to the open surgical release of the A1 pulley. We present our outpatient-based, hypodermic needle release of A1 pulley of triggering finger for chronic trigger finger with functional recovery. In our 30 digits with triggering complaints for more than 6 months, 20 patients were females. Thumb was involved in 19 cases and Age ranged from 25 to 68 years. Using a hypodermic $18 \mathrm{G}$ needle, the average duration of the procedure including local anaesthesia application was 6 minutes. We observed successful results in $97 \%$ of cases, one trigger finger needed open release after the persistence of symptoms. No complication was observed in any case during the follow-up period. Hypodermic Needle based release of A1 pulley for trigger finger is a safe, cost-effective, reliable, reproducible procedure with acceptable functional outcome, and we recommend this procedure for chronic trigger finger management.

Keywords: chronic trigger finger, hypodermic percutaneous release, functional outcome

\section{Introduction}

Trigger finger or stenosing tenosynovitis is a condition characterized by pain, swelling, limitation of the finger movements and triggering/clicking sensations in the finger. This condition generally involves thumb and ring finger but can be seen in other fingers as well ${ }^{[1]}$. The primary pathology is the thickening of the A1 pulley with resultant entrapment of the flexor tendon, forming a stenosing/triggering mechanism ${ }^{[2]}$. There is a mismatch between the tendon sheath and tendon passing through it ${ }^{[3,4,5]}$. With time there is a nodule formation at A1 pulley due to fibrocartilaginous metaplasia, resulting in entrapment of flexor tendon and forming a triggering mechanism ${ }^{[6,7]}$.

Most often the trigger digit is idiopathic in aetiology, predominantly occurring in middle-aged females. The other etiological factors include direct repetitive tendon trauma, diabetes mellitus, carpal tunnel syndrome, de Quervain tenosynovitis, rheumatoid arthritis, hypothyroidism, mucopolysaccharidosis, amyloidosis, gout, hypertension, tumours and neoplasia ${ }^{[8,9,10]}$.

The initial treatment of trigger digits is conservative, including non-steroidal antiinflammatory medication, finger and hand splints, and steroid injections with satisfactory outcome ${ }^{[11,12]}$. However, when the conservative treatment fails, surgical release of A1 is the treatment of choice with known complications like infection, nerve injury, scar tenderness and contracture ${ }^{[13,14,15,16]}$. Percutaneous release of trigger finger was first described in 1958 with the use of fine tenotome ${ }^{[17]}$, followed by the use of a hypodermic needle in 1992 with high success rates and avoiding complications associated with open release ${ }^{[18]}$.

This study aimed to evaluate the clinical outcome of percutaneous needle release of the chronic trigger digits on an outpatient basis. 


\section{Materials and Methods}

This was a hospital-based outpatient study of chronic trigger finger/digits of the patients treated with percutaneous release of A1 pulley using a hypodermic needle $(18 \mathrm{G})$ between May 2016 to December 2017. 30 digits in 28 patients were included in the study, with 20 females and 9 males. The age group range was from 25 to 68 years. The thumb was involved in 19 cases, ring finger in 8 cases, middle finger in 2 , and index finger in 1 case. The duration of triggering in the finger was an average of 6 months, ranging from 2 months to 3 years. The patients included in this study were satisfying the following criteria

1. The cases are unresponsive to the conservative treatment including at least one injection of local steroid injection.

2. Triggering of finger for more than 3 months duration.

3. Patient convinced for the surgery, after explaining the nature, pathology and treatment modalities of the trigger finger

The triggering of the digits was graded as per the grading system of Ha Ki19 (table1) Patients with grades II, III and IV who have not responded to conservative treatment with a duration of symptoms of more than 6 months were taken for this study.

\section{Surgical procedure}

After proper informed consent and explanation about the surgical procedure, the patients were prepared on Outpatient Basis for the percutaneous hypodermic Needle release of the A1 pulley. Baseline investigations and serology for viral markers were done. The procedure was performed under local Anaesthesia. The point of triggering of the digit was localized by digital palpation, and the proximal and distal edge of the A1 pulley was noted. The proximal edge of the A1 pulley corresponds to the metacarpal-phalangeal crease of the thumb, the proximal crease of the index finger, halfway between the proximal and distal palmar crease of the ring and little finger

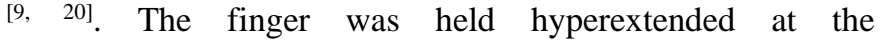
metacarpophalangeal joint which causes flexor tendon sheath to lie directly anteriorly just beneath the skin, and allows the digital neurovascular bundle to displace to either side ${ }^{[5,7,20]}$. The needle is introduced into the Middle of the A1 pulley with the bevelled end of the needle lying along the long axis of the finger. The needle is then swivelled forward and backwards through the pulley, feeling the resistance and continued till the resistance is lost and the patient is instructed to flex and extend the finger as before the symptoms appear.

\section{Results}

The average operation time was six minutes, ranging from 5 to 11 minutes including the application of local anaesthesia? After the release, the pressure was applied over the point of needle insertion for about 3 minutes for haemostasis and the antiseptic dressing was applied for one day only with full mobility of the finger advised. The patients were followed regularly with the first visit within one week to look for the persistence of the triggering and complications after the procedure, the final evaluation was done at 3 months after the release. The outcome was measured as per the Quinells criteria 21 (table 2).

The successful results were observed in $97 \%$ of cases with excellent results in $73 \%$ and good results in $24 \%$ of the cases. In one patient, there was the persistent triggering of the ring finger, the open surgical release was done, the distal edge of the A1 pulley was found intact and released, relieving the triggering. In our series there was no case with complaints attributable to the Neurovascular injury to the digit, no postoperative infection was seen in any patient.

\section{Discussion}

Stenosing tenosynovitis/ trigger finger is a condition with multiple treatment modalities, the use of NSAIDS, splinting and steroid injections at trigger finger is widely accepted in literature with a success rate ranging from $57 \%$ to $97 \%[8,10,22$, 23, 24]. In a series of 108 trigger digits, Marlex and Gutter found a success rate of $92 \%$ with single use of steroid injection at local site and $97 \%$ cure rate with repeated injections.24. Corticosteroid injections seem more useful in acute to semi-acute cases of trigger digits than in chronic cases, the success rate being $88 \%$ when used within one month of the diagnosis of trigger digit and $65 \%$ when used at 6 months or after 6 months of the triggering of the digits ${ }^{[25]}$. Some studies even report only a $55 \%$ success rate when the finger is symptomatic for more than 6 months ${ }^{[26,27]}$. Failure of the conservative treatment is the reason for the surgical release of the A1 pulley of the trigger finger/digit ${ }^{[28]}$. The open surgical release of the A1 pulley has a $100 \%$ satisfactory result with a $28 \%$ complication rate ${ }^{[28,4,20,29]}$. Percutaneous release of trigger digits produced good results in almost all cases without any neurovascular complication in a series of

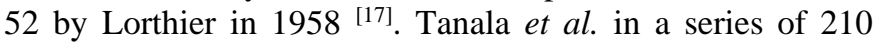
trigger digits with the percutaneous release by fine scalpel reported $64.3 \%$ excellent, $9.5 \%$ good, $8.1 \%$ fair and $18.1 \%$ poor results30. Using a special blade with hook end, Ha $e$ al. ${ }^{[19]}$ reported a $92 \%$ (in 79 Patients) success rate, followed by Park et al. in $2004{ }^{[31]}$ using the same knife reproduced success rate of about $91 \%$. Percutaneous release of A1 pulley using $21 \mathrm{G}$ hypodermic needle, Eastwood et al. reported a success rate of $94 \%$ in 199218 . Contrary to the proximity of the Digital nerve to the A1 pulley of the thumb, there is the reproducible satisfactory clinical outcome in percutaneous A1 release of thumb $[3,5,7,9,32,15,33,19,31,34]$. To prevent nerve damage, the needle is kept above the tendon in the middle of the thumb and the radial approach should be avoided15, the needle is inserted a few millimeters distal to the MCP flexion crease, the thumb is held in full extension during the procedure to make pulley and tendon to lie anterior to $\mathrm{NV}$ bundle and lastly, the thumb should be placed in hypersupination to keep the palmar surface of thumb in the horizontal plane for good orientation. The success rate with percutaneous release of A1 pulley is reported to be $91-100 \%$ with none having any evidence of nerve injury $[21,33,15,33,5]$.

We had a success rate of $97 \%$, with one case presenting as incomplete symptom resolution, which needed open complete release of the pulley. There was no case of infection, nerve injury and bowstring effect after percutaneous Needle release. The percutaneous hypodermic needle release of A1 pulley is a convenient, easy, cost-effective, reproducible and well acceptable method of surgical release of chronic trigger finger, with no need of sophisticated Operation room set-up and anaesthetic machines. The procedure produces the same amount of pain sensation as with a simple needle prick at the time of local anaesthesia application, there onwards the procedure remains fairly painless and active finger movements help in ensuring adequate A1 release.

Conclusion; percutaneous needle release for trigger digits is an easy, safe, reliable, reproducible, acceptable procedure on an outpatient basis. 
Table 1: Showing grades of severity of Triggering

\begin{tabular}{|c|c|}
\hline Grade of triggering & Symptoms \\
\hline I & No triggering but uneven finger movements \\
\hline Ii & Actively correctable triggering \\
\hline Iii & Triggering usually corrected by other hand \\
\hline Iv & Locked digit \\
\hline
\end{tabular}

Table 2: Quinells criteria for functional outcome

\begin{tabular}{|c|c|c|}
\hline Grade & Symptoms & Functional outcome \\
\hline I & Normal movement, no pain & Excellent \\
\hline Ii & Normal movement, occasional pain & Good \\
\hline Iii & Uneven movement & Poor \\
\hline Iv & $\begin{array}{c}\text { Intermediate locking, actively } \\
\text { correctable }\end{array}$ & Poor \\
\hline V & Locking, only passively correctable & Poor \\
\hline
\end{tabular}

\section{References}

1. Bonnici AV, Spencer JD. A survey of 'trigger finger' in adults. J Hand Surg Br 1988;13:202-203.

2. Sampson SP, Badalamente MA, Hurst LC, Seidman J. Pathobiology of the human A1 pulley in trigger finger. $\mathrm{J}$ Hand Surg Am 1991;16:714-721.

3. Joy AK, Brogen AK, Wangjam K, Singh I, Bimol N, Nilachandra L. Percutaneous release of trigger fingers: Is it reserved for few surgeons? IJPMR 2002, 14.

4. Kolind-Sorensen V. Treatment of trigger fingers. Acta Orthop Scandinav 1970;41:428-432.

5. Cihantimur B, Akin S, Ozcan M. Percutaneous treatment of trigger fingers followed 0.5-2 years. Acta Orthop Scand 1998;69(2):167-168.

6. Sampson SP, Badalamente MA. Pathology of the human A1 pulley in trigger finger. $J$ Hand Surg 1991;16(4)A:714-721.

7. Cebesoy O, Karakurum G, Kose KC, Baltaci ET, Isik M. Percutaneous release of the trigger thumb: Is it safe, cheap and effective? International Orthopaedics (SICOT) 2007;31:345-249.

8. Nimigan AS, Ross DC, Gan BS. Steroid injections in the management of trigger fingers. Am J Phys Med Rehabil 2006;85:36-43.

9. Saldana MJ. Trigger digits: diagnosis and treatment. J Am Acad Orthop Surg 2001;9:246-252.

10. Murphy D, Failla JM, Koniuch MP. Steroid versus placebo injection for trigger finger. $\mathbf{J}$ Hand Surg 1995;20A:628-631.

11. Patel MR, Bassini L. Trigger fingers and thumb: when to splint, inject, or operate. J Hand Surg Am 1992;17:110113.

12. Urbaniak JR, Roth JHm. Office diagnosis and treatment of hand pain. Orthop Clin North Am 1982;13:477-495.

13. Carrozzella J, Stern PJ, Von Kuster LC. Transection of radial digital nerve of the thumb during trigger release. J Hand Surg Am 1989;14:198-200.

14. Ryzewicz M, Wolf JM. Trigger digits: Principles, management, and complications. J Hand Surg 2006;31A:135-146.

15. Maneerit J, Sriworakun C, Budhraja N, Nagavajara P. Trigger thumb: results of a prospective randomised study of percutaneous release with steroid injection versus steroid injection alone. J Hand Surg (British \& European volume) 2003;28(6):586-589.

16. Carrozella J, Stern PJ, Von Kuster LC. Transection of radial digital nerve of the thumb during trigger release. J Hand Surg (Am) 1989;14(2):198-200.

17. Lorthioir J. Surgical treatment of trigger-finger by a subcutaneous method. J Bone Joint Surg 1958;40A:793795.

18. Eastwood DM, Gupta KJ, Johnson DP. Percutaneous release of trigger finger: an office procedure. J Hand Surg 1992;17A:114-117.

19. Ha KI, Park MJ, Ha CW. Percutaneous release of trigger digits. A technique and results using a specially designed knife. J Bone Joint Surg (Br) 2001;83B:75-77.

20. Bain GI, Turnbull J, Charles MN, Roth JH, Richards RS. Percutaneous A1 pulley release: A cadaveric study. J Hand Surg 1995;20A:781-784.

21. Ragoowansi R, Acornley A, Khoo CT. Percutaneous trigger Finger release: the 'lift-cut' technique. British Journal of Plastic Surgery 2005;58:817-821.

22. Patel MR, Bassini L. Trigger fingers and thumb: When to splint, inject, or operate. J Hand Surg 1992;17(1):110113.

23. Lambert MA, Morton RJ, Sloan JP. A controlled study of the use of local steroid injection in the treatment of trigger finger and thumb. J Hand Surg (British and European volume) 1992;17(1):69-70.

24. Marks MR, Gunther SF. Efficacy of cortisone injection in the treatment of trigger fingers and thumb. J Hand Surg 1989;14A:722-729.

25. Turowski GA, Zdankiewicz PD, Thomson JG. The results of surgical treatment of trigger finger. $\mathrm{J}$ Hand Surg 1997;22A:145-149.

26. Newport ML, Lane LB, Stuchin SA. Treatment of trigger finger by steroid injection. J Hand Surg 1990;15:748-750.

27. Rhoades CE, Gelberman MD, Manjarris JF. Stenosing tenosynovitis of the finger and thumb. Clin Orthop 1984; 190:236-238.

28. Makkouk AH, Oetgen ME, Swigart CR, Dodds SD. Trigger finger: aetiology, evaluation, and treatment. Curr Rev Musculoskelet Med 2008;1:92-96.

29. Vaes F, Smet LD, Ransbeeck HV, Fabry G. Surgical treatment of trigger fingers. Acta Orthopaedica Belgica 1998;64(4):363-365.

30. Tanaka M, Muraji M, Negoro H, Yamashita H, Nakano T, Nakano K. Subcutaneous release of trigger thumb and fingers in 210 fingers. J Hand Surg (British and European volume) 1990;15(4):463-465.

31. Park MJ, Oh I, Ha KI. A1 pulley release of locked trigger digit by percutaneous technique. J Hand Surg (British and European volume) 2004;29B:502-505.

32. Blumberg N, Arbel R, Dekel S. Percutaneous release of trigger digits. J Hand Surg (British \& European volume) 2001;26(3):256-257.

33. Schramm JM, Nguyen M, Wongworawat MD. The safety of percutaneous trigger finger release. Hand 2008;3:4446.

34. Patel MR, Moradia VJ. Percutaneous release of trigger digit with and without cortisone injection. J Hand Surg 1997;22A:150-155. 